\title{
SOCIEDAD DE LA INFORMACIÓN: REDES SOCIALES EN ENTORNOS DIGITALES. REDES NACIONALES DE TELECENTROS EN LA REGIÓN ANDINA
}

Por

Jorge Mauricio Escobar Sarria ${ }^{1}$

Profesor Universidad Autónoma de Occidente.

Cali, Colombia

jescobar@uao.edu.co

\section{Resumen:}

Este texto plantea una reflexión panorámica sobre la sociedad de la información como noción y discurso actual predominante; sobre sus implicaciones para Colombia y algunas definiciones de las redes sociales a través de entornos digitales. De igual manera, referencia casos, experiencias y presenta los discursos institucionales de las redes nacionales de telecentros, ligando reflexiones entre las nociones teóricas - conceptuales y sus experiencias de aplicación ${ }^{1}$.

\section{Palabras claves:}

sociedad de la información, comunicación, redes sociales, entornos digitales, telecentros comunitarios y redes nacionales de telecentros.

\footnotetext{
${ }^{1}$ Comunicador Social - Periodista. Magíster en Educación con énfasis en Educación Popular y Desarrollo Comunitario. Estudiante del Doctorado de Información y Documentación (Universidad de Zaragoza - España). Miembro del Grupo de Investigación en Comunicación para el Desarrollo
} 


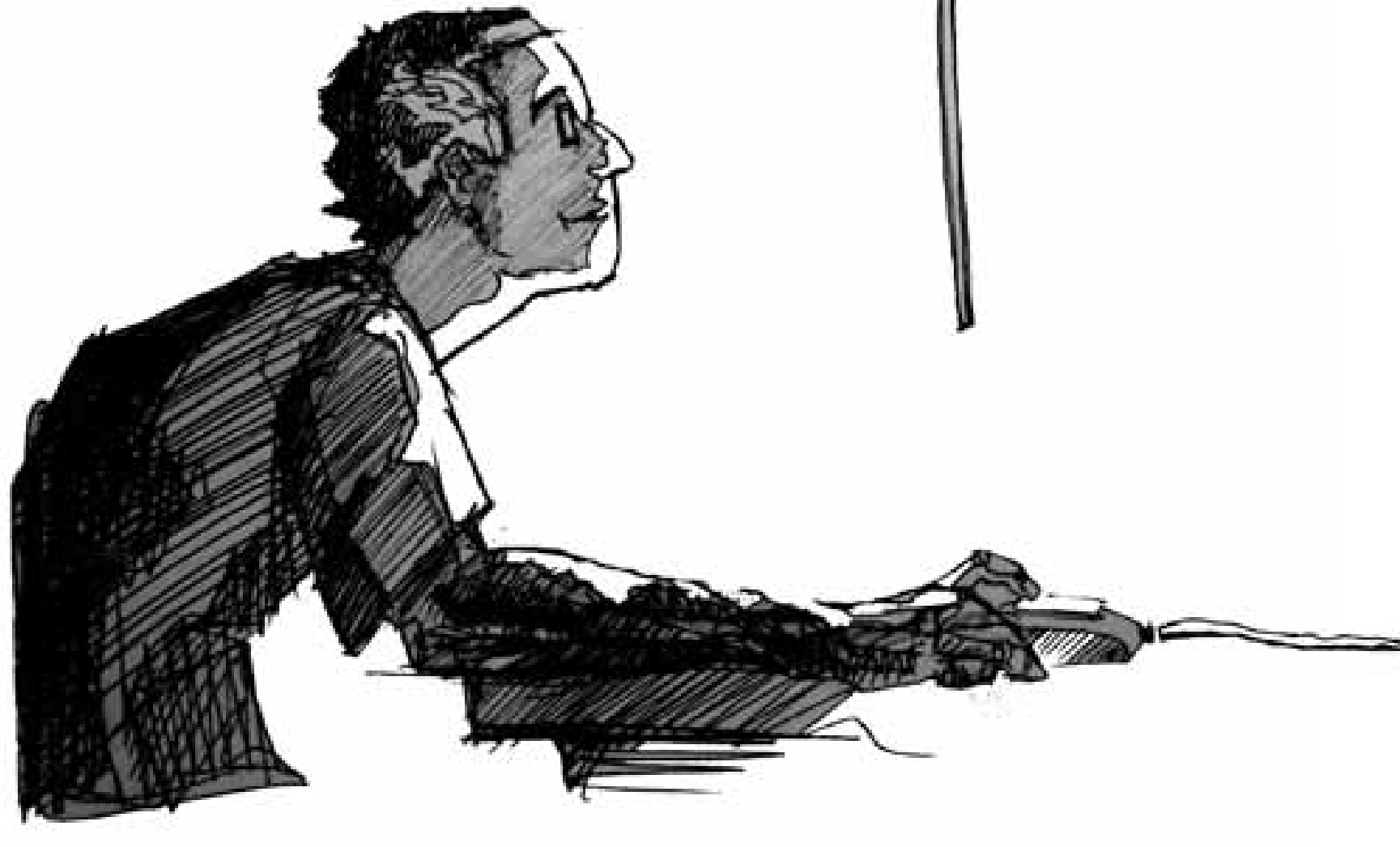

\section{Desde la sociedad de la información}

En la llamada Sociedad de la Información, la "Sociedad Estallada" está referida a la multiplicidad de prácticas discursivas, con supuestos escenarios compartidos, que fragmentados y diseminados por las redes y autopistas de información reciben los actores y organizaciones sociales cada día.

Este discurso y tendencia mundial, está soportado en los avances en las telecomunicaciones, los nuevos escenarios económicos y la promesa de mundos equitativos y accesibles para todos: "garantizar una distribución equitativa de los recursos, facilitar el acceso de todos y garantizar un funcionamiento estable y seguro de Internet... Reafirmamos nuestro compromiso de dar a todos un acceso equitativo a la información y los conocimientos, en reconocimiento de la función de las TIC para el crecimiento y el desarrollo económico" (Unión Internacional de Telecomunicaciones - UIT, 2005: 45).

Entre tanto, los proyectos y los estudios de TIC, se han fundamentado en las prioridades sobre el acceso y la conectividad (calidad y cobertura: reducción de la brecha digital, que conlleva directamente la brecha social), como enfatiza el Profesor Jesús Martín Barbero (2004). Por el contrario, aún existe desconocimiento y pocas investigaciones sobre las TIC para el desarrollo en las comunidades, sus procesos, transformaciones de sus prácticas, sus representaciones y sus modos de vida en la red.

Sin embargo, por una necesidad sentida o circunstancial, los enfoques y formas de articulación del uso de las TIC en diferentes procesos sociales, están migrando a una vertiginosa velocidad a fenómenos de intercambio, casos, experiencias, aprendizajes significativos y espacios colaborativos que apoyan la configuración de comunidades en redes sociales - redes virtuales, y hechos de sentido (Abril, 2007) que determinan nuevos escenarios de discusión, reflexión, tensión y estudio académico. 
Los diferentes discursos que han referido a la sociedad de la información y el conocimiento, contrastan las experiencias de aplicación (entiéndase proyectos, programas y/o estudios) impera la discusión del régimen del saber; como los modos válidos de adquirir y organizar el conocimiento; discutiendo la validez del conocimiento local tradicional y el conocimiento representativo.

El documento de "Colombia Visión 2019 - Avanzar hacia una sociedad mejor informada", proclama el sector de las TIC como uno de los principales impulsadores del crecimiento económico y del desarrollo social del país, contribuyendo a la consolidación de una sociedad informada, conectada e integrada al entorno global y diversos centros de investigación, observatorios y programas que soportan los estudios oficiales sobre la sociedad de la información para Colombia.

Los estudios, las indagaciones preliminares y estados del arte sobre las TIC, evidencian intentos por recopilar y sistematizar dinámicas y experiencias representativas, como un mero modismo formal que encuentra encrucijadas en los enfoques metodológicos, el sentido informacional y la rendición de cuentas para las agencias de cooperación, los cofinanciadores y/o los programas de Estado ${ }^{2}$.

"Las versiones teórica y empíricamente más fundadas de la SI la conciben como el producto de una asociación multidimensional entre las TIC y ciertas formas de organización social y económica, en cierta medida preexistentes. Siguiendo la terminología de Bell (1976) y la caracterización de Castells (1997) la SI puede ser descrita, de forma muy esquemática, como la conjunción entre un modo de producción (una forma reestructurada de capitalismo) y un modo de desarrollo (el informacionalismo) específicos" (Aibar, 2008: 15).

No obstante, comprender las concepciones de comunicación y trabajo en red, implica la revisión de las incidencias que tiene la construcción de redes de intercambio de información y conocimiento en la multiplicidad de discursos en contra y a favor de la tecnología: apocalípticos e integrados (Eco, 1994).
Los detractores de la tecnología referencian los fenómenos de circulación de conocimiento (saber social: conocimiento tácito e implícito) y connotan la reflexión sobre los escenarios de transmisión que no permiten ver las siluetas (lectura de contexto y entorno) para revelar los intereses e intercambios requeridos (necesidades) y los aspectos formales solicitados por la institucionalidad $\mathrm{y} / \mathrm{o}$ los proyectos.

Se insiste en distinguir que la información no es solo contenido, objeto y producto, sino un proceso múltiple y complejo (Abril, 1997), que discute y difiere sobre el reparto entre "poseedores" y "desposeídos" del acceso de la información y el conocimiento.

"Ninguna tecnología tiene por sí misma la capacidad para reconfigurar la experiencia colectiva pues su acción se cruza con una gran cantidad de interacciones (Martín Barbero, 2000), y la capacidad de la sociedad para transformarse se expresa en el poder que tiene para manipular el objeto. El diseño de nuevas formas de ser es, entonces, uno de los retos que se nos presenta al adoptar las nuevas tecnologías en nuestro espacio social y despierta toda una nueva capacidad para experimentarlas y pensar otro tipo de sociedades" (Tamayo, Delgado y Penagos, 2007: 252).

Ahora bien, desde una mirada crítica de la llamada panacea de acceso a la información, se evidencia que el acceso a las TIC no garantiza conocimiento. Uno de los mayores detractores de esta evidencia, son los repositorios (portales web), que solo almacenan información y fracturan la posibilidad de acercamientos a la relaciones de reciprocidad e igualdad para generar dinámicas de intercambios y acercamientos de las comunidades a conocimientos propios y validados como prácticos en su quehacer cotidiano.

"Al hacernos creer que el acceso vía Internet al 'saber universal', que forzosamente saldrá de los monopolios de los conocimientos, podría resolver el problema no sólo de la fractura digital, sino de la fractura social, los expertos en educación de las grandes instituciones financieras, tales como el Banco Mundial, le insuflan una nueva juventud a la concepción difusionista del desarrollo que podría haberse tenido por obsoleta al 
quebrar las estrategias inspiradas en la ideología cuantitativa de la modernización. La sociedad de las redes está lejos, pues, de haber terminado con el etnocentrismo de los tiempos imperiales. Antes que resolver el problema, la tecnología lo desplaza”

(Vizer, 2004:39).

En 1998 el IDC, World Times Information Society, plantea los índices de la sociedad de la información (retomados en Colombia, por el Conpes 3072 del 9 de febrero de 2000) donde se enfatizó en (3) tipos de infraestructuras: primero, infraestructura de computacional (mide la capacidad de un país para recibir, manipular y transmitir información digital a través de computadores personales y el Internet). Segundo, infraestructura de información (mide la capacidad de recibir y enviar información en formatos de voz, texto y video). Tercera y última, infraestructura social (mide la capacidad que tengan los ciudadanos de aprovechar a las Tecnologías de la Información y la Comunicación). De igual manera acentúa la relevancia de indicadores sobre los porcentajes de líneas telefónicas, los aparatos de radio, los aparatos de televisión, los aparatos fax, los teléfonos celulares per cápita, el cubrimiento televisión por cable/ satelital y el costo de una llamada local.

Sin embargo, resalta la necesidad de los indicadores de computadores per cápita, computadores adquiridos en hogar, en los centros educativos, en uso para el gobierno y el comercio, los usuarios de Internet en hogar, en el comercio y la educación, la inversión en hadware y software, terminando con el porcentaje de computadores conectados a una red. Desde la perspectiva de la infraestructura social, se refiere al grado de escolaridad (bachillerato y universidad), libertad de prensa, libertad civil y penetración de la prensa escrita.

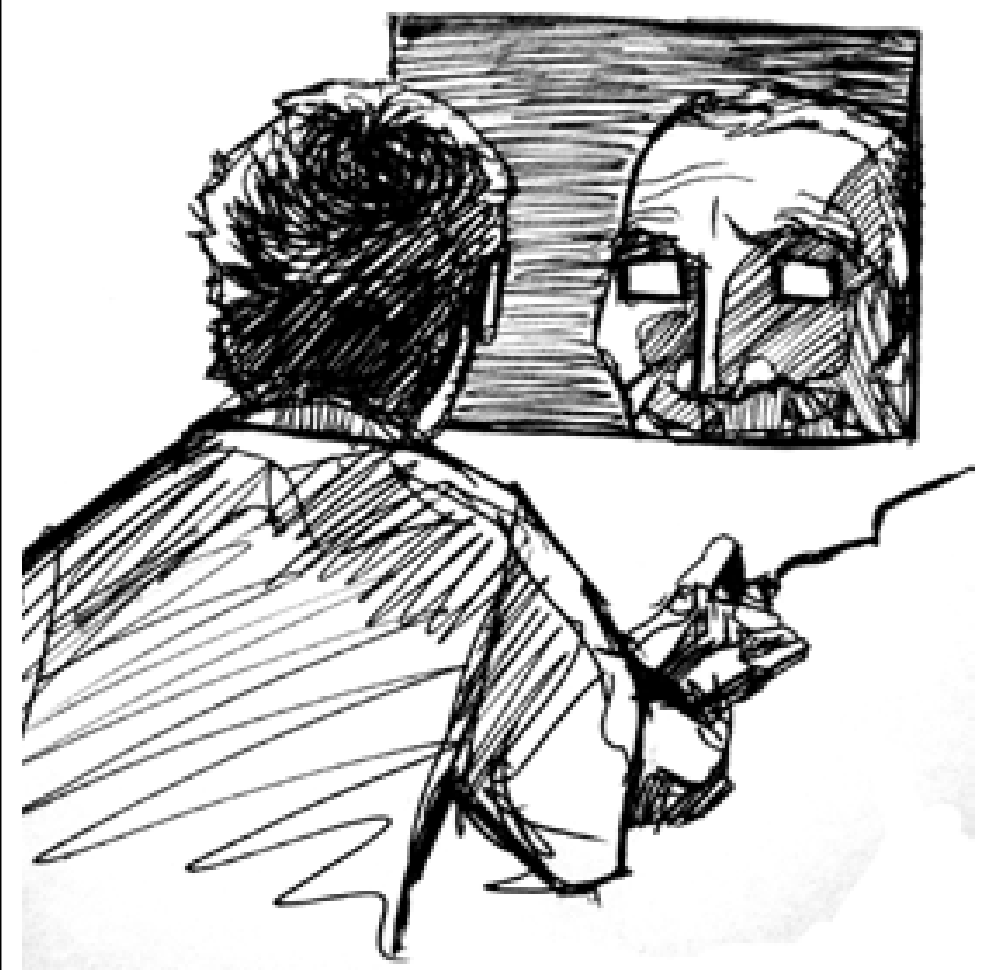

En Colombia, el Plan Nacional de TIC, tiene como misión "lograr un salto en la inclusión social y en la competitividad del país a través de la apropiación y el uso adecuado de las TIC, tanto en la vida cotidiana como productiva de los ciudadanos, las empresas, la academia y el Gobierno".

El reto más significativo para enfrentar desde el Gobierno Nacional en la sociedad información en Colombia, es el cumplimiento de Plan Nacional de Tecnologías de la Información y las Comunicaciones 2008-2019. Destacándose algunos indicadores del pacto social digital (Ministerio de Tecnologías de la Información y las Comunicaciones, 2010), relacionados con los usuarios de Internet en banda ancha por cada 100 habitantes, los computadores por cada 100 habitantes, el promedio de estudiantes por computador en instituciones educativas y/o centros educativos públicos, el número de Phd en el área de TIC y el porcentaje de ciudadanos que realizaron trámites o solicitaron servicios haciendo uso del Gobierno en línea. 
Una de las estrategias claves "Colombianos conectados e informados" se resume en (5) enfoques: masificar la conectividad de Internet y de banda ancha (beneficiar de conectividad en banda ancha las instituciones públicas como telecentros, promover la penetración de Internet a nivel nacional, incorporación de nuevas tecnologías inalámbricas y acceso a TIC para población discapacitada), masificación de computadores (financiación y dotación de $\mathrm{PC}$ a diferentes grupos poblacionales), apropiación y generación de capacidades en TIC (creación de formación de alto nivel e implementación de estrategias de alfabetización y disminución de la brecha digital), interacción del ciudadano con el Estado a través de las TIC (ampliar y mejorar los servicios de Gobierno en Línea, promover el uso de intranet y apoyo a la I+D) y territorios digitales (formulación y aplicación de territorios digitales y generar la cultura digital en las regiones).

De acuerdo con la Comisión de Regulación de Comunicaciones (CRC) y el portal del sistema de información unificado (SIUST), sus informes de conectividad documentan que hay 3.309.530 usuarios de Internet (marzo de 2010). Los accesos dedicados fijos aumentaron un 4,25\%, mientras que los accesos móviles por suscripción se incrementaron en 5,4\%. Este crecimiento se debe al incremento en 78.708 en las conexiones de acceso fijo y a la incorporación de 49.391 nuevos accesos a través de redes móviles, durante el primer trimestre del año.

Los accesos fijos conmutados y dedicados alcanzaron en total los 2.344.859, a marzo de 2010, lo que significa un incremento del 3,47\%, en éste tipo de acceso, respecto del trimestre anterior. De acuerdo con el Barómetro de la Banda Ancha de Cisco (empresa líder de redes para Internet), reportó un crecimiento del $11.7 \%$ durante el primer semestre de 2010, siendo el 44\% de las conexiones concentradas en Bogotá y el $56 \%$ en el resto del país.

Este panorama da cuenta de avances interesantes, pero no muestra los fenómenos de eclosión de redes sociales en entornos digitales donde usuarios/navegantes casuales, circunstanciales y/o propositivos en las redes comunitarias (community networks) privilegian un discurso emergente de acciones solidarias, cambios sociales e intercambios de experiencias y conocimientos.
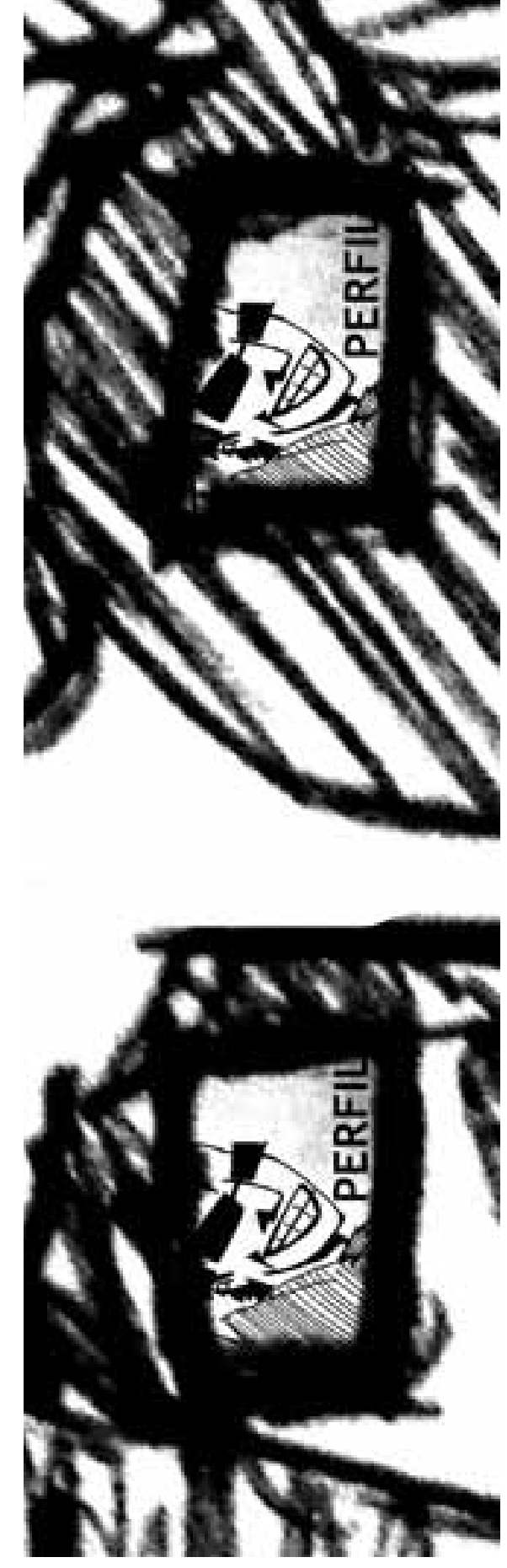

"En la tierra viven 6.896 millones de personas. De ellas, más de 2.000 millones son internautas, según un informe de la ONU, es decir, un 29\% de la población mundial o uno de cada tres humanos. Un gran dato que se empequeñece si se compara con la penetración de la telefonía móvil, que cubre a 7 de cada diez personas. Casi un tercio de la humanidad navega en Internet".

Fuente: Portal ITU (http://www.itu.int/net/pressoffice/stats/2011/01/index.aspx) 


\section{Redes sociales en entornos digitales}

El fenómeno de las redes sociales consolidado no solo por el masivo Facebook, Tuenti, Baddo, Myspace y Twitter, ha convertido a las comunicaciones medidas por tecnologías en un intenso y nuevo espacio de socialización. Desde intercambios de conocimiento, experiencias significativas, casos, gestión del conocimiento y grupos de discusión, crecen exponencialmente como adicción del nuevo homo digital ${ }^{3}$.

Esta manera de socialización mediada por las TIC, sin espacios y marcas temporales facilita una presencia en red, en supuesta libertad. Se convierte pues, en una burbuja envolvente que lleva consigo la consulta, la participación activa y/o la interacción, que garantiza el acceso a la dinámica a la red respectiva.

Entre las diversas nociones de las redes sociales, se destaca una común, sobre las "formas de interacción social, definida como un intercambio dinámico entre personas, grupos e instituciones en contextos de complejidad. Un sistema abierto y en construcción permanente que involucra a conjuntos que se identifican en las mismas necesidades y problemáticas y que se organizan para potenciar sus recursos” (Larrañaga, 1996: 15).

Ahora bien, se diferencia la red social de la plataforma web que permite el intercambio. "En general, las redes sociales digitales son definidas como "servicios basados en la web que permiten a sus usuarios relacionarse, compartir información, coordinar acciones y en general, mantenerse en contacto [...] [espacios que] permiten reconstruir o mantener, en el mundo virtual, los vínculos que alguna vez se establecieron en el mundo físico (Bacallao, 2010: 119).

Por lo tanto, la interacción social va transformándose progresivamente y se verán reforzadas por necesidades, coyunturas, amistades y relaciones a distancia, que reafirman el concepto de usabilidad, como la relación hombre (usuario) y máquina-tecnología (computador/ Internet).

En general las redes promueven pequeñas sociedades fragmentadas (cadenas ciudadanas), minorías con vínculos de apariencia, de coherencia y de simbiosis que multiplican los usos y prácticas de TIC, donde la red es el nuevo espacio de descanso, de ocio y de vida en un espacio virtual permanente (un ejemplo, http://www. secondlife.com/).

"Facebook 500 millones de usuarios, Hotmail tiene unos 361 millones de usuarios, Yahoo!, 273 millones, y Gmail, unos 193 millones de usuarios”.

Fuente: ComScore, 2010. Portal: (http://www.comscore.com/esl/) 
Entre las fortalezas y debilidades de la participación en redes sociales se destacan conjeturas como la modificación de formas de redacción del periodismo tradicional, el intercambio de información con personas, colegas y profesionales con afinidades temáticas, las novedosas propuestas de contenidos, los grupos de cooperación y solidaridad, contrastado por la reducción de dedicación efectiva a las horas laborales, la suplantación de identidades, plagios, el individualismo y las conversaciones simultaneas, la adicción a las redes sociales y la búsqueda infinita de contactos, la emergencia de virus y delitos informáticos.

Las redes sociales propician la interacción de personas con base en un sistema global de relaciones entre individuos basados en la estructura social, como plantea Georg Simmel. Otra noción, define que las redes son: "un grupo de personas que comparten una preocupación, un conjunto de problemas o un interés común acerca de un tema, y que profundizan en su conocimiento y pericia en esta área a través de una interacción continuada" (Wenger, McDermott y Snyder, 2002: 78).

Así que las redes sociales pueden funcionar $\mathrm{y}$ desarrollar proyectos para crear intercambios de conocimientos (experiencias) más allá de límites organizativos o institucionales. De hecho la red constituye un nuevo paradigma social y económico en que nos hemos instalado en las últimas décadas y que ha ido denominando "sociedad red".

Otro enfoque planteado por Abello, Madariaga y Sierra en 1998, definen la red social como un conjunto de relaciones humanas que tienen un impacto duradero en la vida de cualquier persona. La red social está conformada por los sujetos significativos cercanos al individuo y constituye su ambiente social primario.

Desde la formalidad, una red es un entramado de vínculos sociales, que une, siquiera temporal o superficialmente, a distintas personas entre sí. Una red social no implica entonces relaciones estrechas o permanentes entre las personas.
Una definición común de la red social implica el conjunto bien definido de actores- individuos, grupos, organizaciones, comunidades, sociedades globales, etc. - que están vinculados unos a otros a través de una o un conjunto de relaciones sociales (De la Rua, 2005).

Partiendo desde la teoría que planteada por Anthony Giddens (1991), las redes sociales y las redes virtuales, son organizaciones formales, que por ser grupos secundarios, (entiéndase grupos secundarios como grupos numerosos con orientación instrumental o material y los une un objetivo específico, no se ven involucrados emocionalmente y la lealtad no es uno de los vínculos, las relaciones son efímeras y reemplazables) creados a propósito para un llevar adelante unos objetivos preestablecidos.

El auge de los espacios de intercambio y redes en entornos digitales, hacen pensar la creación y consolidación de las llamadas comunidades virtuales. Jesús Salinas, en el texto Comunidades virtuales y aprendizaje digital, propone: "Una comunidad virtual, en definitiva, viene a ser la experiencia de compartir con otros que no vemos un espacio de comunicación. La atracción por la red y por la participación en este tipo de experiencias viene dada por la habilidad de la tecnología para legitimar públicamente la propia expresión y por la libertad que proporciona en relación a las barreras tradicionales del espacio y del tiempo".

Twitter ya alcanzó los 200 millones de usuarios quienes tuitean un promedio de 110 millones mensajes por día. Apenas en septiembre del 2010 Twitter "solo" tenía 160 millones de usuarios, ahora tiene 200 millones. Un aumento de cuarenta millones en cuatro meses es un porcentaje bastante impresionante; recordando que Twiter empezó en el 2006. Fuente: ComScore, 2010. 
En definitiva, es clave considerar las 'redes virtuales' como entornos basados en web que agrupan personas relacionadas con una temática específica que además de las listas de distribución (primer nodo de la red virtual) comparten documentos, recursos, experiencias, casos, información, etc. Estas redes virtuales serán tanto más exitosas, cuanto más estén ligadas a tareas, acciones colectivas o a perseguir intereses comunes juntos.

\section{Algunos casos en las redes nacionales de telecentros}

Las redes nacionales de telecentros en algunos países de la región andina (Colombia, Ecuador, Perú y Bolivia) han liderado interesantes procesos de construcción de redes sociales desde las perspectivas y reflexiones antes mencionadas. Estos procesos tienen recurrente apoyo y cofinanciación del Instituto Internacional para la Comunicación y el Desarrollo (IICD, Países Bajos - www.iicd.nl), el Centro Internacional de Investigaciones para el Desarrollo (CIID / IDRC, Canadá - www.idrc.org) y telecentre.org (http://telecentre-comunidad.ning.com/), denominada por ellos mismos, como "comunidad global de personas y organizaciones comprometidas con el aumento en cantidad y calidad del impacto social y económico de los telecentros comunitarios".

En adelante se retoma los discursos oficiales de las diversas iniciativas de redes nacionales andinas, que configuran una muestra de casos que están presentes en la relación entre la academia, las organizaciones no gubernamentales y algunos programas de Estado.

En Colombia la Red Nacional de Telecentros (www.telecentros.org.co) es el resultado de una serie de esfuerzos políticos y sociales orientados desde la sociedad civil y desde iniciativas gubernamentales que desean proporcionar el escenario adecuado para la convergencia de la mayoría de actores que trabajan con telecentros en Colombia.

Los telecentros comunitarios o centros de acceso público (también llamados cibercafé, telecabañas, infocentros, tecnocentros, infoaulas, cabinas, locutorios, infocalis, punto común, clubes digitales, centros de acceso a Internet, etc.) son considerados, de manera sucinta como: "lugares de encuentro, aprendizaje y comunicación donde se ofrecen las TIC como medios para mejorar las condiciones de vida de las comunidades" (Red Nacional de Telecentros de Colombia, 2010). 
La Red busca abrir espacios de diálogo y reducir la brecha entre las iniciativas de telecentros lideradas desde el gobierno y las experiencias orientadas desde centros de investigación, universidades, ONGs, organizaciones sociales entre otras.

Esta experiencia, nace formalmente en septiembre de 2008, con la firma del convenio especial de cooperación interinstitucional para la consolidación de la Red Nacional de Telecentros en Colombia, con el esfuerzo de diversas organizaciones privadas, sociales y públicas, entre las que se destacan y lideran la Universidad Autónoma de Occidente de Cali, a través de su grupo de investigación de Comunicación para el Desarrollo, la Asociación Colombiana de Organizaciones no gubernamentales vía correo electrónico (Colnodo) con sede en Bogotá, la Corporación Makaia con sede en la ciudad de Medellín y el Ministerio deTecnologías de la Información y las Comunicaciones de Colombia.

Se unen posteriormente, la Universidad del Cauca, con el Grupo de investigación en Telemática, con sede en Popayán, la Corporación Colombia Digital con sede en Bogotá, Empresa de Telecomunicaciones de Bogotá (ETB S.A - ESP) y Compartel como programa de "telecomunicaciones sociales cuyo objetivo es permitir que las zonas apartadas y los estratos bajos del país se beneficien con las tecnologías de las telecomunicaciones como son la telefonía rural y el servicio de Internet”4

La construcción participativa definió la misión de la red, como un "ente integrador de diferentes iniciativas y organizaciones que buscan el desarrollo y fortalecimiento de los telecentros, de las personas que los administran y de las comunidades a través del uso productivo e impacto social de las TIC. Así mismo, es interlocutor que representa los intereses de quienes administran telecentros y están en regiones alejadas sin posibilidades de diálogo con quienes toman decisiones".

Espera entonces, promover estrategias que permitan la inclusión digital de diferentes poblaciones del territorio colombiano, la articulación de actores y redes locales que lideran iniciativas de TIC, la definición y ejecución de planes y políticas en este campo y el intercambio de experiencias y aprendizajes para el fortalecimiento de telecentros y de la Red.

Un programa clave de la experiencia de telecentros, es el proceso de formación y capacitación a más de 600 personas a través de la Academia Nacional de Telecentros (www.telecentros.org.co/academia) tanto para la comunidad como para las personas que administran telecentros, todo ello, con una perspectiva transversal de equidad que permite la inclusión de diversos actores: mujeres, población étnica, personas en situación de discapacidad, adultos/as mayores, entre otros.

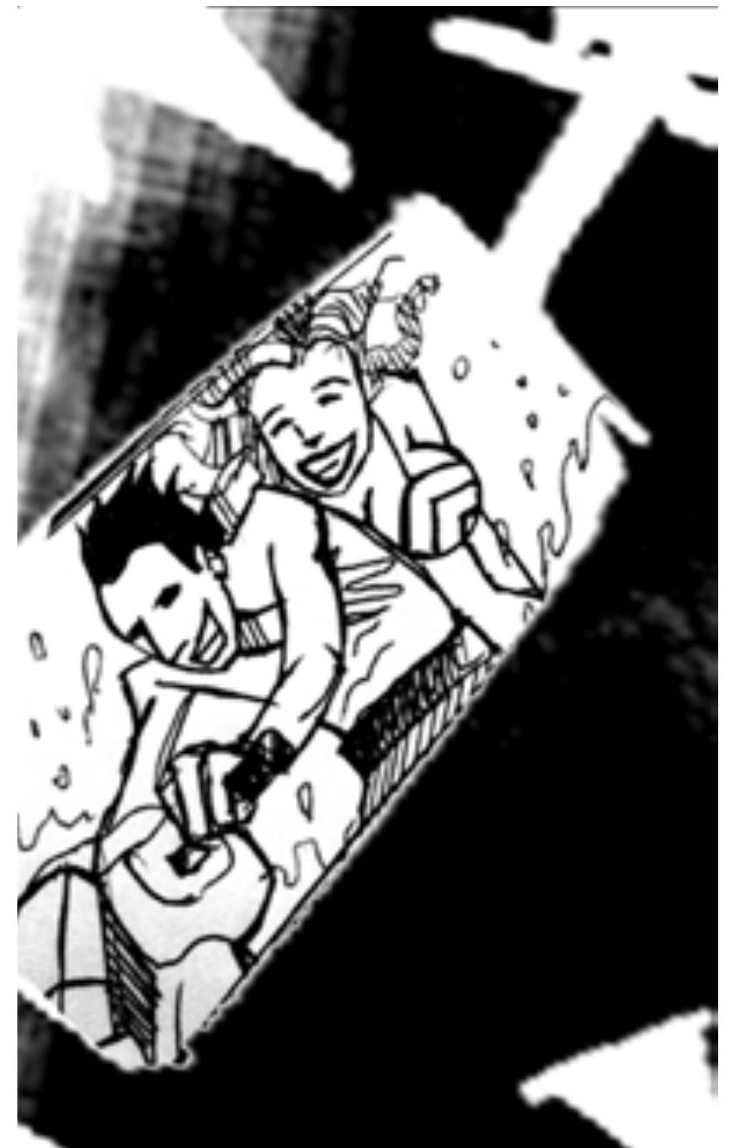




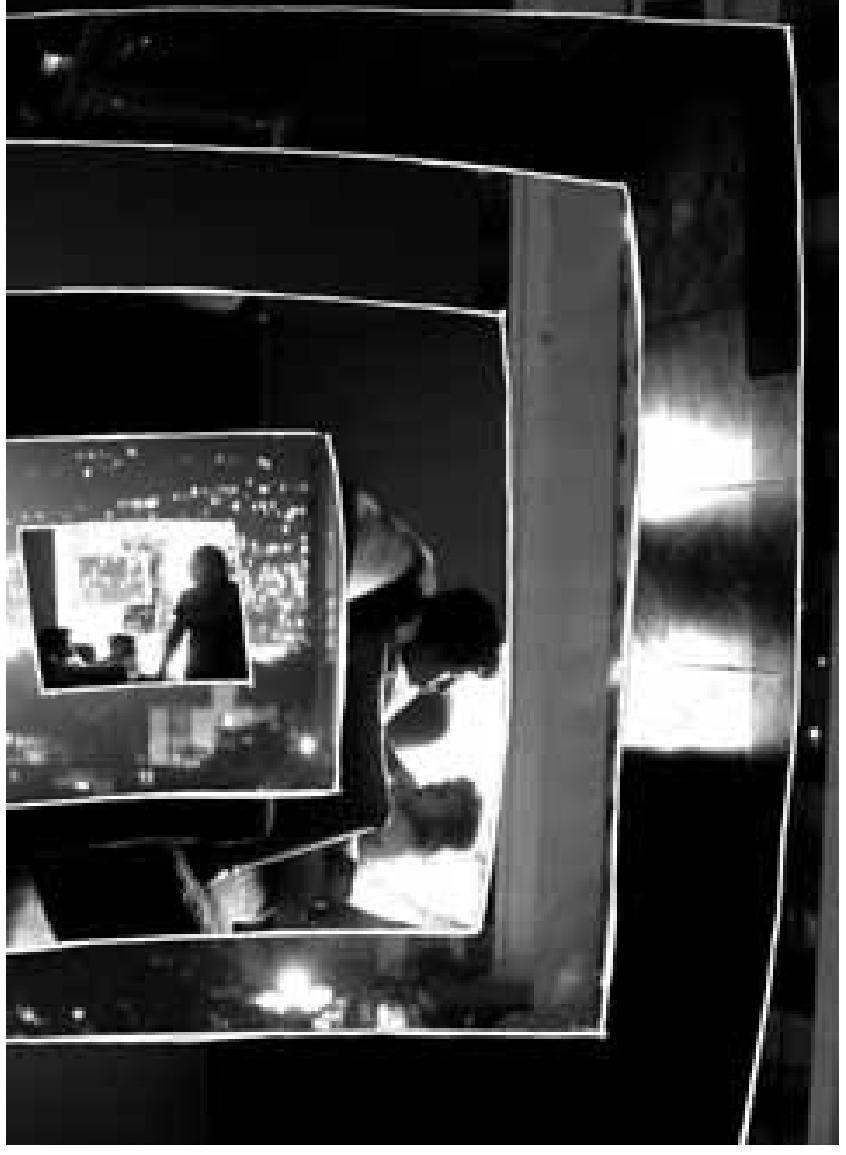

Para el caso de la Red Nacional deTelecentros de Ecuador (http://www.infodesarrollo.ec) está liderada desde la Corporación Red Infodesarrollo, considerada como la red ecuatoriana de Información y Comunicación para el Desarrollo, conformada por 35 organizaciones. Su misión es “promover la generación eintercambio de información, metodologías, experiencias y conocimientos sobre TIC para el desarrollo, y fomentar procesos participativos multisectoriales en políticas públicas alrededor de este tema en el Ecuador. De esta manera, reducir la duplicación de esfuerzos y dar a conocer el potencial del uso estratégico de estas herramientas para el cumplimiento de los objetivos de desarrollo del país y del mundo" (Brochure Infodesarrollo).

La visión construida de forma colectiva propone "una red multisectorial con miembros activos y participativos que promueva espacios de intercambio de conocimientos y sensibilización, como referente en la construcción de un entorno político regulatorio adecuado, para que la sociedad ecuatoriana aproveche las TIC como una herramienta estratégica para el desarrollo social, cultural, político y económico del país”.

Los objetivos principales de red son intercambiar conocimientos, compartir metodologías y lecciones aprendidas sobre el uso de las TIC para el Desarrollo, promover procesos de participación multisectorial en políticas públicas en la utilización de las TIC en diferentes sectores de desarrollo.

Las líneas estratégicas que se esperan desarrollar están encaminadas en el fortalecimiento de la comunicación interna y externa de la red, consolidar la estructura de la red, fortalecer el trabajo alrededor de los ejes temáticos (desarrollo rural, educación, y gobernabilidad), ser actores y referentes de incidencia en políticas de TIC a nivel nacional y asegurar la sostenibilidad de la red. Se enfatiza desde los ejes transversales de equidad de género y social, acceso y conectividad y políticas públicas.

Se destacan algunas de las entidades participantes como la Asociación de Mujeres de las Juntas Parroquiales Rurales del Ecuador, la Universidad Jatun Yachay Wasi, el Instituto Nacional de Capacitación Campesina, Facultad Latinoamérica de Ciencias Sociales (Flacso - Ecuador), Escuelas Populares Radiofónicas del Ecuador, Acción Ecológica, Centro de Investigación para la Sociedad de la Información, la Fundación de Organizaciones Campesinas de Salinas, Nuevared.org, la Universidad Politécnica Salesiana, el Ceped/ Radio La Luna, la Universidad Estatal de Bolívar y Fundación Tierra Azul, entre otras. 
Las actividades claves de la Red Infodesarrollo (Ecuador) son el observatorio Ecuatoriano de Políticas Públicas de TIC, las investigaciones, publicaciones y sistematizaciones, foros electrónicos, talleres, seminarios, foros, conversatorios, cartillas y videos sobre TIC para el desarrollo.

En la experiencia de Perú de configuración de redes de telecentros se destacan procesos de diferente naturaleza, la primera de telecentros rurales

(www.telecentros.pe) en manos de una entidad dedicada a la investigación y capacitación INICTEL UNI adscrito a la Universidad Nacional de Ingeniería, con actividades de montaje de infraestructura, fortalecimiento y desarrollo para 28 distritos y 24 telecentros rurales, siendo "una red para contribuir al desarrollo social, económico y cultural a través del acceso y manejo apropiado de las TIC", en zonas de Lima, Huancavelica, Puno, Cuzco y Ancash.

De forma paralela, el Centro Peruano de Estudios Sociales (Cepes) ${ }^{5}$ ha promovido diversos proyectos de iniciativas de TIC para el desarrollo, uno de los más destacados el proyecto de Asistencia a responsables de Telecentros de América Latina (http:/ / telecentrecomunidad.ning.com/) liderado por Juan Fernando Bossio.

Se reportan diversas iniciativas entre las cuáles se mencionan el Sistema de información agraria delValle del Hural (www.hural.org), el Instituto Rural Valle Grande, Cañete (www.irvg.org), Piura Rural (www.piurarural.com), SADA, Arequipa (www.sira-arequipa.org.pe), AEDES, Arequipa (www.aedes.com.pe/), Llampanet, Chiclayo (www.llampanet.org), EHAS, (www.ehas.org), Atecnodis, (www.atecnodis.org/), La Casa de Panchita (www. gruporedes.org/), Las Bambas (www.asociacioncallpas.org), Alternativa, Lima (www.alter.org.pe) y CERIN@P, Lima (www.munimolina.gob.pe/), entre otros, que han realizado actividades conjuntas de formación, reflexión, intercambio y encuentros nacionales sobre apropiación de TIC.

Para el caso de Bolivia, la Red Nacional incluye ONGs, organizaciones sociales de base, empresas privadas y entidades gubernamentales cuyas finalidades son: "Promover y compartir experiencias en el uso y la aplicación de Tecnologías de Información y Comunicación (TIC) en todos los ámbitos del desarrollo, influir en políticas públicas y abogar por el uso de TIC en pro del desarrollo sostenible” (Información institucional).

"Es en ese escenario y ante esa realidad construida desde la base que la RedTicBolivia pretende ser un referente articulador de las instituciones y organizaciones que utilizan y ejecutan proyectos que usando las Tecnologías de Información y Comunicación (TIC) busquen el Desarrollo Humano Sostenible en todos sus ámbitos con una visión de equidad de género y justicia social" (portal TicBolivia).

Actualmente está conformada por 17 organizaciones que ejecutan proyectos de desarrollo con componente TIC en los sectores de agricultura, gobernabilidad, educación y desarrollo local, promueven y comparten experiencias en el uso de las TIC, como insumo clave para influir en las políticas públicas y sensibilizar sobre el uso, particularmente centrados en el desarrollo humano.

En resumen, las iniciativas de redes nacionales de telecentros en algunos países de América Latina, tiene interesantes, convergentes y reiterados programas y procesos. 
Cuadro 1. Mapeo de Redes de Nacionales de Telecentros en Colombia, Ecuador, Perú y Bolivia

\begin{tabular}{|l|c|l|}
\hline \multicolumn{1}{|c|}{ País } & $\begin{array}{c}\text { Número de iniciativas } \\
\text { registradas }\end{array}$ & \multicolumn{1}{c|}{ Web(s) } \\
\hline $\begin{array}{l}\text { Colombia } \\
\text { Lidera Colnodo }\end{array}$ & $\begin{array}{c}1.426 \text { iniciativas } \\
917 \text { personas }\end{array}$ & $\begin{array}{l}\text { http://www.telecentros.org.co/ } \\
\text { http://mapeo.telecentros.org.co/ }\end{array}$ \\
\hline $\begin{array}{l}\text { Ecuador } \\
\text { Lidera Infodesarrollo }\end{array}$ & 116 iniciativas & $\begin{array}{l}\text { http://www.infodesarrollo.ed/ } \\
\text { http://www.infodesarrollo.ee/telecentros// }\end{array}$ \\
\hline $\begin{array}{l}\text { Perú } \\
\text { Lideran Cepes } \\
\text { INICTELUNI. }\end{array}$ & $\begin{array}{c}30 \text { iniciativas } \\
\text { aproximadamente }\end{array}$ & $\begin{array}{l}\text { Mapa de telecentros y cabinas públicas del } \\
\text { Perú } \\
\text { Portal en construceión }\end{array}$ \\
& $\begin{array}{l}\text { Telecentros Rurales del INICTitos } \\
24 \text { telecentros }\end{array}$ & http://www.telecentros.pe/telecentros-earth/ \\
\hline $\begin{array}{l}\text { Bolivia } \\
\text { Lidera Red TICBolivia }\end{array}$ & 448 iniciativas & $\begin{array}{l}\text { http://www.telecentremap.org/index.php/es_ES } \\
\text { home/index/country/Bolivia/ }\end{array}$ \\
\hline
\end{tabular}

Fuente: Construcción del autor. Diciembre de 2010.

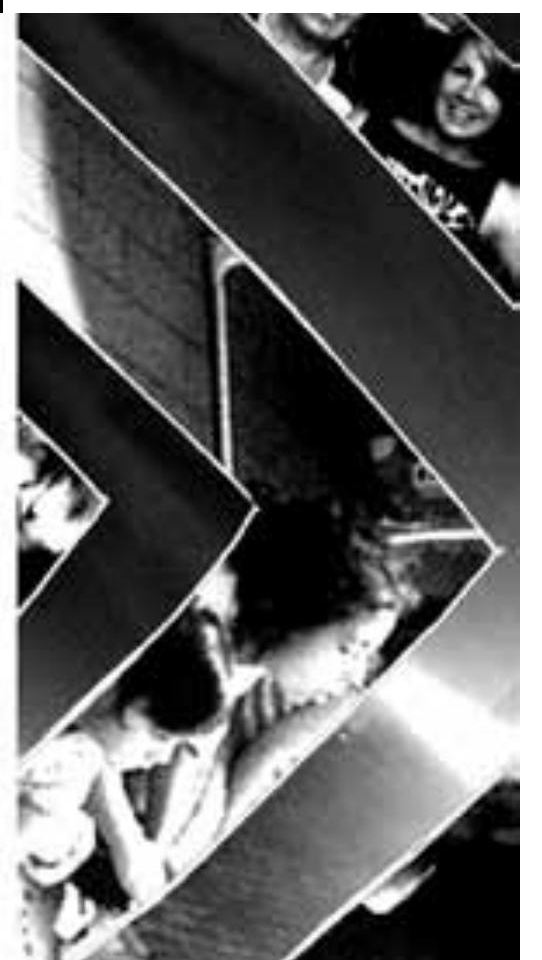

Previo a los proyectos y redes nacionales de telecentros antes descritas, desde la Fundación Chasquinet en Ecuador, en 1999, se creó y consolidó la Red Latinoamericana y del Caribe de Telecentros -

somos@telecentros (http://www.tele-centros.org), que se define como "una red humana de telecentros comunitarios, organizaciones sociales e iniciativas que compartimos realidades similares y nos acompañamos en el desarrollo de actividades y proyectos, a través de diálogos e intercambios de información y conocimiento", con el propósito de facilitar círculos de aprendizaje, comunicación apoyo, acompañamiento, gestión del conocimiento y acción entre personas que sueñan en un mundo mejor y, para ello, invierten su experiencia y esfuerzo en investigar, mejorar, adaptar, intercambiar y aplicar soluciones prácticas a la vida de sus comunidades, basadas en el potencial de las TIC, pero con un uso con sentido de las mismas.

En 2002 esta red realizó el primer estudio sobre el estado del arte de los telecentros en América Latina y el Caribe, caracterizando y compilando las experiencias desde los telecentros y los trabajos en red.

Para terminar este acápite, se referencian algunas redes nacionales de telecentros en otros países que desde la llamada sociedad civil vienen liderando y cogestionando en múltiples escenarios. 
Cuadro 2. Algunas iniciativas de

redes nacionales de telecentros

\begin{tabular}{|c|c|}
\hline Iniciativa y Web & Objetivo(s) \\
\hline $\begin{array}{l}\text { Asociación de Telecentros Activos de Chile } \\
\text { (ATACH) } \\
\text { Creada en } 1997 \\
\text { Web: } \\
\text { http://telecentrosatach.ning.com/ } \\
137 \text { iniciativas }\end{array}$ & $\begin{array}{l}\text { "Institución de caracter gremial que tiene como propósito } \\
\text { contribuir a la disminución de la brecha digital, logrando la } \\
\text { inclusión social de personas y grupos vulnerables a través del } \\
\text { uso y apropiación de las TIC". }\end{array}$ \\
\hline $\begin{array}{l}\text { Telecentros de Brasil } \\
\text { Observatorio de inclusión digital } \\
\text { Web: http://www.onid.org.br/mapa/ } \\
8.062 \text { iniciativas }\end{array}$ & $\begin{array}{l}\text { "ONID é uma iniciativa articulada pelo Governo Federal em } \\
\text { interlocuçocom a sociedade civilorganizada como objetivo de } \\
\text { acompanhar e avaliar as aç̃es de inclusão digital no Brasil". }\end{array}$ \\
\hline $\begin{array}{l}\text { Telecentros de Informatica (Argentina) } \\
\text { Creada en } 2005 \\
\text { Web: } \\
\text { http:/www.telecentros.org.ar } \\
8 \text { iniciativas de diversa indole }\end{array}$ & $\begin{array}{l}\text { "Iniciativa de inclusion digital que colabora fuertemente en } \\
\text { la inclusion social y desarrollo de la ciudadania, sin plantar } \\
\text { ambos como excluyentes. Es un lugar donde los más pobres } \\
\text { aprenden en forma colectiva el uso de las nuevas tecnologias, } \\
\text { investigan y producen conocimientos útiles para mejorar la } \\
\text { calidad devidade su comunidad, se informan de sus derechos, } \\
\text { entablan relaciones con otras comunidades". }\end{array}$ \\
\hline $\begin{array}{l}\text { Red de Infocentros en Venezuela } \\
\text { Creada en } 2007 \\
\text { Web: http://www.infocentro.gob.ve } \\
240 \text { Iniciativas }\end{array}$ & $\begin{array}{l}\text { "Fortalecer el desarrollo de las potencialidades locales, las redes } \\
\text { sociales y el poder popular. Para ello facilitamos el proceso de } \\
\text { apropiación de las TiC por parte de los sectores populares, } \\
\text { mediante la consolidaciónde espacios tecnológicos comunitarios } \\
\text { que faciliten la construccióncolectivay transferencia de saberes } \\
\text { y conocimiento, las relaciones de colaboración y de } \\
\text { coordinación, la generación de redes y la comunicación popular, } \\
\text { para hacer de esta plataforma tecnológica una herramienta para } \\
\text { la solución de problemas y de transformación de la realidad". }\end{array}$ \\
\hline $\begin{array}{l}\text { Red Nacional de Telecentros de España } \\
\text { Creada en } 2003 \\
\text { Web: http://www.telecentros.es } \\
40 \text { provincias. }\end{array}$ & $\begin{array}{l}\text { "Facilitar el acceso a las nuevas tecnologias tanto a las } \\
\text { poblaciones rurales como a los colectivos menos integrados, a } \\
\text { fin de lograr su participación efectiva en la Sociedad de la } \\
\text { Información". }\end{array}$ \\
\hline
\end{tabular}

Fuente: Construcción del autor. Diciembre de 2010.

\section{Consideraciones finales}

Luego del rastreo básico sobre la sociedad de la información, las redes sociales en entornos digitales y los casos de las redes nacionales de telecentros, se plantean tres (3) consideraciones finales (a manera de preguntas) que permiten una reflexión sobre un sinnúmero de iniciativas, proyectos y políticas públicas que de manera recurrente mantienen protagonismo en los escenarios regionales, nacionales e incluso internacionales. 
Los proyectos de TIC con énfasis en redes nacionales han tenido directa colaboración de agencias de cooperación internacional, especialmente de Canadá, Países Bajos, Españay Estados Unidos. Esta cooperación tiene una fuerte incidencia en los propósitos, objetivos y énfasis de las iniciativas apoyadas. La cofinanciación combina recursos de infraestructura, asesoría, asistencia técnica, intercambios, formaciones y capacitaciones de especialistas y expertos en procesos de incorporación de uso estratégico de tecnologías para el desarrollo.

Los proyectos de cooperación internacional para el desarrollo están sustentandos en reducción de brecha digital (conectividad, computadores, infraestructura) en el caso de los proyectos con el Estado directamente, con diferencias sustanciales para las ONGs que con menores presupuestos centralizan esfuerzos en capital humano, consolidación de procesos y formación que apoyen la sostenibilidad, enfatizando el trabajo colaborativo y apropiación de la red por parte de los miembros.

Los programas de cooperación y apoyo se sustentan en la llamada marginalidad informacional (inforicosinfopobres): fractura digital, que velado con el acceso a las TIC, esconden las tecnologías de comunicación como formas de poder y formas de dominación promoviendo el tecnocomunitarismo, a través de acciones solidarias colectivas y globales (Matterlard, 2002).

Uno de los dilemas más complejos y escondidos en estas propuestas de cooperación es la sustentabilidad y sostenibilidad de los proyectos. Los indicadores de logro y fuentes de verificación, de carácter cuantitativo, desconocen las incidencias e impactos de los procesos puestos en marcha. No hay ningún estudio serio y riguroso que permita identificar los avances y reales impactos de esas propuestas.
Los proyectos cofinanciados tienen "supuesta" independencia, pero obedecen a un marcado interés en políticas del circuito de la sociedad de la información (modelo y discurso unificado) que cumplen con sus estrategias y los programas de acuerdo con procesos transnacionales y globales, donde la factibilidad y continuidad de las redes promovidas, las dinámicas y proyectos no son sostenibles en el tiempo con la misma calidad, cobertura y objetivos iniciales. ¿Cuál es el trasfondo e interés en la creación y apoyo de iniciativas de esta naturaleza?

\section{¿Auto legitimación?}

Todo ejercicio de organización y consolidación de grupos de trabajo está mediado por los llamados procesos de consenso y legitimación de los participantes. La validez y pertinencia de los miembros autopostulados, elegidos y/o seleccionados siempre tendrán discusión. Las redes como medios para organizar y transmitir información se convierten en la fuente de poder e instrumento de dominación de un escenario privilegiado que le facilita cogestionar, organizar, presupuestar y figurar en el liderazgo.

Sin embargo, se debe tener en cuenta que la legitimación de liderazgo en una red, está mediada por una auto legitimación (pequeños poderes, autonombramientos) que garantizan posiciones de privilegio, información de primera mano, capacidad de interlocución con agentes decisores y adaptación de discursos institucionales a patrones de cofinanciación, con acuerdos de conveniencia y en el fondo de manera directa, recursos de fondeo para las organizaciones participantes o líderes de la red.

Es decir, no es una simple y desprevenida acción de cooperación para el desarrollo llena de buenos propósitos sino que también, intereses y relaciones directas con la construcción de escenarios que faciliten diversos apoyos y avales en la medida que la red se fortalezca y demuestre dinámicas de participación activa de los beneficiarios/usuarios. 
En definitiva, la pregunta sobre auto legitimación y auto nombramiento para participar en una red, está sustentada en válidos intereses institucionales que refuerzan las nociones antes mencionadas de redes sociales como grupo de personas que comparten una preocupación, problemas o un interés común acerca de un tema. ¿Por qué se auto legitima un miembro de una red?

¿Casos y experiencias? Mucho por mostrar...

Los llamados casos exitosos, experiencias y aprendizajes significativos rondan el mundo de las redes sociales. Los hechos casuísticos y los números como hechos demostrativos documentan los esfuerzos de proyectos que se han convertido en iniciativas de ejemplo para otros. Con criterios como participación comunitaria, ejercicios de perspectiva de género, procesos participativos, integración de jóvenes, apropiación social de TIC, se seleccionan experiencias que consideran relevantes como muestrario de otras iniciativas.

Uno de los planteamientos claves para encaminar la discusión está soportado en la facilidad de los líderes para consolidar "las redes globales de intercambios instrumentales que conectan y desconectan de forma selectiva individuos, grupos, regiones o inclusos países según la importancia para cumplir las metas procesadas en la red, en una corriente incesante de decisiones estratégicas" (Matterlard, 2006: 76). Por ello, la selección de casos y experiencias, parte de criterios que seguramente tienen toda la pertinencia e idoneidad, acompañada de buenas intenciones.

Para terminar, se puede inferir que los casos seleccionados son un acto de intencionalidad que apuesta a mostrar cualidades ideales, situaciones positivas, testimonios a favor que permiten unificar juicios de valor sobre el proceso en la red, necesarios en proyectos de cooperación que deben mostrar resultados benáficos en las comunidades. ¿Qué casos y experiencias se consideran significativos para promover los proyectos de trabajo en red?

A manera de cierre, mencionamos una metáfora que asemeja la definición de la red como una maraña entendida como el conjunto de hebras bastas, enredadas y de grueso desigual, que en la parte inferior soportan de manera invisible lugares de encuentro mediados por las TIC que emplean y soportan el tejido de las relaciones.

En conclusión, el discurso recurrente de índice de oportunidad digital, índice de preparación para la interconexión, el reporte global de disponibilidad de gobierno en línea, infraestructura en telecomunicaciones y las metas de desarrollar capacidades en la población para el uso y la apropiación de las TIC y masificar la información, seguirá en contraste con la utopía de internet universal que supuestamente promueve las libertades y las configuraciones de redes sociales como nuevos espacios de interacción social e institucional. 
I En el marco de los proyectos de investigación sobre "Gestión de conocimiento e intercambio de experiencias entre Telecentros Comunitarios y Telecentros Compartel” y “Apropiación social, gestión del conocimiento en Telecentros Compartel y fortalecimiento de la Red Nacional de Telecentros de Colombia”, del Grupo de Investigación de Comunicación para el Desarrollo de la Universidad Autónoma de Occidente, se presenta este artículo sobre la sociedad de la información, las redes sociales en entornos digitales y redes de telecentros nacionales en algunos países de la región andina (Colombia, Ecuador, Perú y Bolivia).

II Ver el estudio realizado por la Universidad de los Andes, "Resumen de la Evaluación del Impacto y Análisis de Viabilidad de los Programas Compartel - Internet Social, Bogotá, 2007”.

III Noción planteada por José B. Terceiro, en el libro Sociedad Digital: del Homo Sapiens al Homo Digital.

Iv Ver el link, http://archivo.mintic.gov.co/mincom/faces/index.jsp?id=6097

$\mathrm{v}$ Ver el portal: http://www.cepes.org.pe

\section{Páginas Web}

http: / / telecentre-comunidad.ning.com/

http: / / vivedigital.gov.co/

http: / /www.alaic.net/portal/

http://www.apc.org/es

http: / /www.cepal.org/socinfo/osilac/

http: / / www.ciespal.net/ ciespal/

http: / / www.colnodo.apc.org/

http://www.comscore.com/esl/

http://www.eclac.org/

http: / / www.idrc.org

http://www.iicd.nl

http: / / www.infodesarrollo.ec/telecentros/

http://www.itu.int/net/pressoffice/stats/2011/01/index.aspx

http://www.mintic.gov.co/

http: / /www.secondlife.com/

http://www.telecentremap.org/index.php/es_ES/home/index/country/Bolivia/

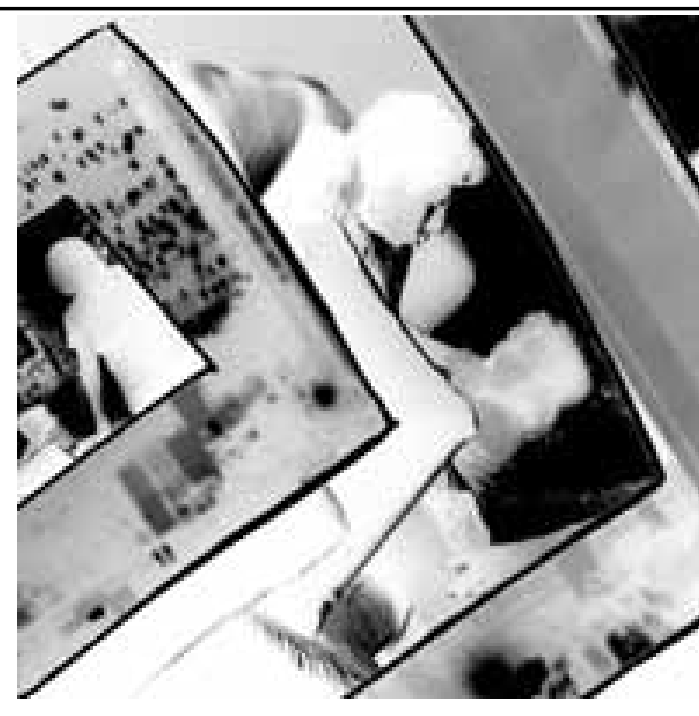

http: / / www.tele-centros.org

http: / / www.telecentros.org.co

http: / / www.telecentros.pe/telecentros-earth/ 


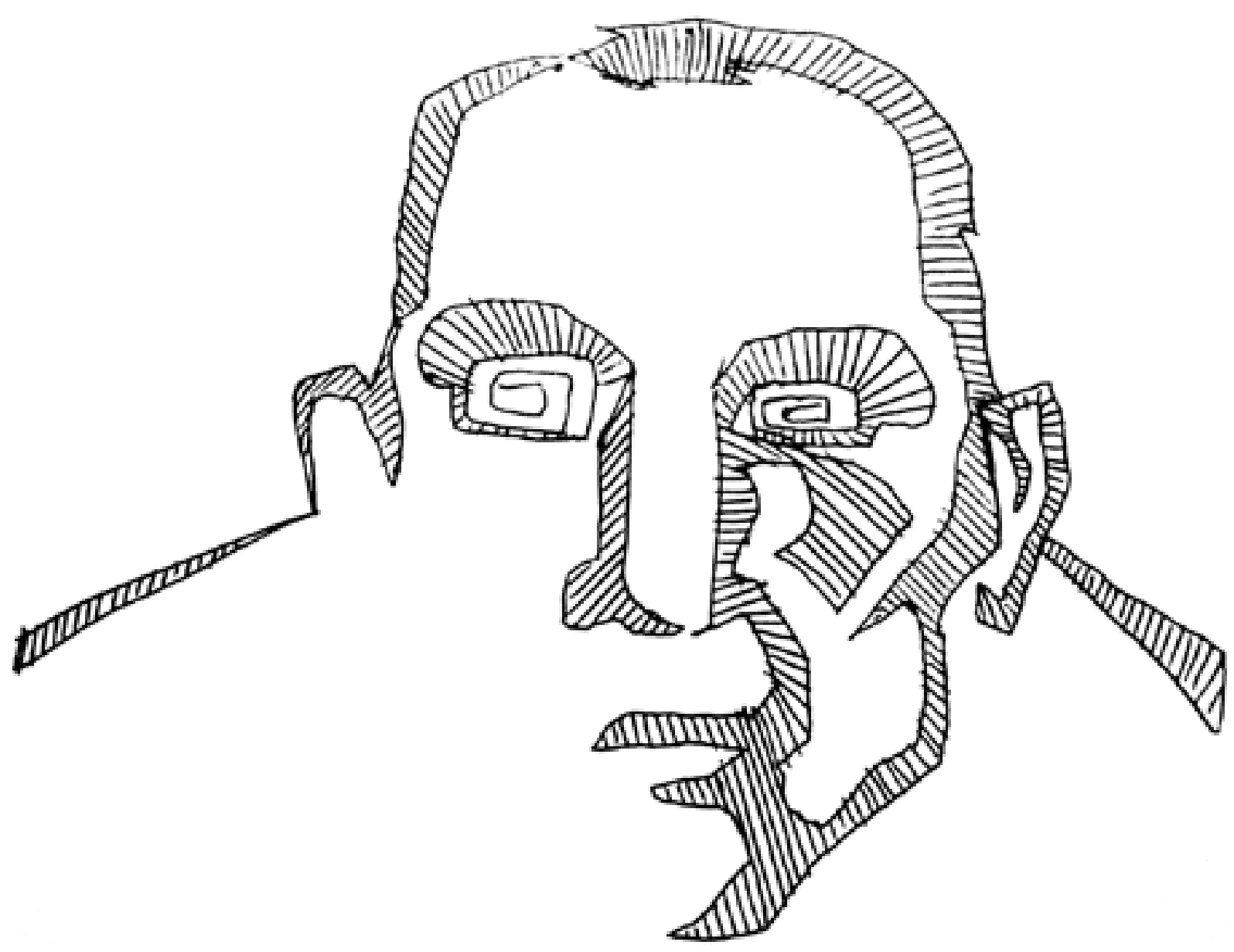

\section{Referencias}

Abello, Raimundo; Madariaga, Camilo; Sierra, Omar. Relaciones entre redes sociales y dinámica familiar de mujeres trabajadoras. Revista Psicología, 1998, vol 2.

Abril, Gonzalo. Teoría general de la información: Datos, relatos y ritos. 1a ed. Madrid: Cátedra, 1997, ISBN 84-376-1495-3.

Aibar, Eduard. Las culturas de Internet: la configuración sociotécnica de la red de redes. Revista Iberoamericana de Ciencia Tecnología y Sociedad, 2008, vol. 4, No 11. p. 9-21.

Bacallao Pino, Lázaro M. (2010): Representaciones mediáticas de las redes sociales: un estudio de casos, en Revista Latina de Comunicación Social, 65, pp. 114 - 125. Disponible en el portal: http:// www.revistalatinacs.org/10/art/887_UZaragoza/09_Lazaro_Bacallao.html

Becerra, Martín. Sociedad de La Información, Proyecto, Convergencia, Divergencia. Signo y Pensamiento, 2003, vol. 22, No 43, p. 169. ISSN 0120-4823.

Bonilla, Marcelo. Las nuevas tecnologías de información y comunicación (NTIC), herramientas de empoderamiento simbólico en América Latina. Cuadernos de Iberoamérica, globalización y nuevas tecnologías: nuevos retos y nuevas reflexiones, Madrid: Organización de Estados Iberoamericanos para la Educación la Ciencia y la Cultura, 2001.

Castells, Manuel. La era de la información: Economía, sociedad y cultura. Madrid: Alianza, 1997. ISBN 8420642479; 8420642460.

Colle, Raymond. Procesos documentales y gestión del conocimiento. Razón y Palabra, 2005, No 46, ISSN 1605-4806.

Colombia. Congreso de la República. Ley 1341 de 2009. Ley TIC. Principios y conceptos sobre la sociedad de la información y la organización de las Tecnologías de la Información y las Comunicaciones -TIC. [en línea]. Bogotá: 2009. [Consultado 13 de Diciembre de 2010]. Disponible en Internet: http://www.secretariasenado.gov.co/senado/basedoc/ley/2009/ley_1341_2009.html 
Colombia. Consejo Nacional de Política Económica y Social (Conpes) 3072 de 2000. “Agenda de Conectividad: el salto a Internet”. Consejo Nacional de Política Económica y Social, 2000. [Consultado 17 de Diciembre de 2010]. Disponible en Internet: www.nsrc.org/ STHAM/CO/conpes.pdf.

(Conpes) 3457 de 2007. Lineamientos de Políticas para Reformular el Programa Compartel de Telecomunicaciones Sociales. Consejo Nacional de Política Económica y Social, 2007. [Consultado 18 de Diciembre de 2010]. Disponible en Internet: www.dnp. gov.co/PortalWeb/Portals/0/archivos/.../Conpes/3457.pdf.

Agenda Regulatoria de Telecomunicaciones 2009 [en línea]. Bogotá: Comisión de Regulación de Telecomunicaciones, 2009. [Consultado 17 de Diciembre de 2010]. Disponible en Internet: www.crcom.gov.co/.

Estudio de alternativas regulatorias para el desarrollo de banda ancha en Colombia. Centro de Conocimiento del Negocio, Comisión de Regulación de Telecomunicaciones (CRT) [en línea]. Bogotá: Comisión de Regulación de Telecomunicaciones, 2007. [Consultado 16 de Diciembre de 2010]. Disponible en Internet: www.crcom.gov.co/.

Comisión de Regulación de Telecomunicaciones (CRT). Informes Sectoriales de Telecomunicaciones. Comisión de Regulación de Telecomunicaciones (CRT) [en línea]. Bogotá: Comisión de Regulación de Telecomunicaciones, 2008 - 2009. [Consultado 17 de Diciembre de 2010]. Disponible en Internet: www.crcom.gov.co/.

. Promoción y masificación de los servicios de banda ancha en Colombia. Comisión de Regulación de Telecomunicaciones (CRT). Colombia. Versión I - II [en línea]. Bogotá: Comisión de Regulación de Telecomunicaciones, 2004 - 2005. [Consultado 18 de Diciembre de 2010]. Disponible en Internet: www.crcom.gov.co/.

CURRIE, William y BETANCOURT, Valeria. Comunicación para el cambio: construyendo redes TICs para el desarrollo. Disponible en Internet: http://www.idrc.ca/es/ev-128708-201-1-DO_TOPIC.html.[Consultada el 12.15.2010].

Departamento Nacional de Estadística (DANE). Indicadores Básicos de Tecnologías de la Información y Comunicación [en línea]. Bogotá: Departamento Nacional de Estadística (DANE), 2008. [Consultado 14 de Diciembre de 2010]. Disponible en Internet: www.dane.gov.co/files/investigaciones/boletines/tic/pres_tic_agos08.pdf.

Departamento Nacional de Planeacion (DNP). Dirección de evaluación de políticas públicas. 2019 Visión Colombia. II Centenario. Avanzar hacia una sociedad mejor informada. ISBN: 958-8025-72-9. 2007.

De la Rúa, Federico. Revista Empiria de metodología de ciencias sociales. No 10,151-184. El análisis dinámico de redes sociales con SIENA - Método, discusión y aplicación. Número especial sobre análisis de redes sociales. Université des Sciences et Technologies de Lille (Francia) Institut Féderatif des Récherches sur les Sociétés Industrielles (IFRESI), diciembre 2005.

Echeverría, Javier. Apropiación social de las tecnologías de la Información y La Comunicación. Revista Iberoamericana de Ciencia Tecnología y Sociedad, 2008, vol. 4, No 10, p. 171-182.

Indicadores cualitativos de la sociedad de la información. Revista Nómadas No 18. Departamento de investigaciones Universidad Central. Mayo de 2003. p. 115 - 123.

Finquelievich, Susana; Kisilevsky, Graciela. La sociedad civil en la Era Digital: Organizaciones comunitarias y redes sociales sustentadas por TIC en Argentina. Documentos de Trabajo (Universidad de Buenos Aires. Facultad de Ciencias Sociales), 2005 , No 41. p. 220 .

Fundación Chasquinet - Somos@telecentros. Estado del arte de los telecentros en América Latina y el Caribe: Quito, Ecuador. Febrero, 2002. Disponible en: http://wsispapers.choike.org/estado_arte.pdf.

García Galindo, Juan Antonio. La Sociedad de la Información (SI): Su historia. Telos: Cuadernos De Comunicación e Innovación, 2009 , No 81, p. 66-79. ISSN 0213-084X.

García Marco, Francisco Javier. Hacía Un Modelo De Intervención en los Procesos de Transmisión Del Conocimiento. Scire: Representación y Organización del Conocimiento, 1995, vol. 1, No 2. p. 106-138. ISSN 1135-3716.

Giddens, Anthony. Cultura, individuo e interacción social. Madrid: Alianza Universidad Textos, 1991.

. Un mundo desbocado. Los efectos de la globalización en nuestras vidas. Madrid: Taurus, 2000.

Gómez, Ricardo; Hunt, Patrik y Lamoureux, Emmanuelle. Telecentros en la mira: ¿cómo pueden contribuir al desarrollo social?. Centro Internacional de Investigaciones para el Desarrollo (CIID - IDRC). 2002-06-21. Disponible en: http://www.idrc.ca/es/ ev-4343-201-1-DO_TOPIC.html.

Hopenhayn, Martín, Ni apocalípticos ni integrados: aventuras de la modernidad en América Latina. Chile: Fondo de Cultura Económica, 1994.

Larrañaga, Irantzu. Internet solidari@, la última revolución. Navarra:Txalaparta S.L. 1996. Citado en: Leon, Osvaldo; Burch, Sally; 
Tamayo, Eduardo. Movimientos sociales en la Red. Septiembre, 2001. Disponible en: http://alainet.org/publica/msred/ Leon, Burch y Tamayo. Movimientos Sociales en la Red. Quito, septiembre de 2001. ISBN: 9978-42-017-7. ALAIC.

Martín Barbero, Jesús. Los desafíos estratégicos de la sociedad de la información. Signo y Pensamiento, 2004, vol. 23, No 44. p. 9-18, ISSN 0120-4823.

Mattelart, Armand. Historia de la sociedad de la información, Barcelona: Paidos, 2002. ISBN 8449311918.

. Pasado y presente de la sociedad de la información: Entre el nuevo orden mundial de la información y la comunicación

y la "Cumbre Mundial Sobre La Sociedad de la Información”. Telos: Cuadernos de comunicación e innovación, 2006, No 67, p. 13-26, ISSN 0213-084X.

Ministerio de Tecnologias de la Información y las Comunicaciones. Plan Nacional de Tecnologías de la Información y las Comunicaciones 2008 - 2019, Bogotá, 2008.

Documento Plan Vive Digital Colombia, Bogotá, 28 de Octubre de 2010.

Pacto social digital 2010 - 2019, informe de junio de 2010. Plan Nacional de Tecnologías de la Información y las

Comunicaciones.

. Resumen de la Evaluación del Impacto y Análisis deViabilidad de los Programas Compartel - Internet Social, Bogotá, 2007.

Paniagua, Enrique [et al.]. La Gestión Tecnológica del Conocimiento, Universidad de Murcia, servicio de Publicaciones, Murcia, 2007, p.321, ISBN: 978-84-8371-661-8.

Paz, Olga Patricia. Políticas de gestión del conocimiento y usos sociales de nuevas tecnologías de información y comunicación, TIC, en tres programas. En Los usos de Internet: comunicación y sociedad, Quito: Facultad Latinoamericana de Ciencias Sociales (Flacso) sede Ecuador: Centro Internacional de Investigaciones para el Desarrollo, 2006, p. 107-202

Telecentros: Hacia el acceso, uso masivo y aprovechamiento de TIC en América Latina y el Caribe. InfoAndina del Consorcio para el Desarrollo Sostenible de la Ecorregión Andina (CONDESAN). Lima, Marzo 3 de 2002, Disponible en: www.infoandina.org/system/files/ recursos/telecentros.pdf.

Pereira, José Miguel. www. Cibersociedad. La Sociedad de la Información y las Comunicaciones. Signo y Pensamiento, 2000, vol. 19, No 36. p. 7-10. ISSN 0120-4823.

Proenza, Francisco. e-Paratodos: Una estrategia para la reducción de la pobreza en la era de la información. En: Organización de las Naciones Unidas para la Agricultura y la Alimentación (FAO), 1984. Disponible en: hppt://www.aat-ar.org/documentos/eParaTodos.

Rau de Almeida, Manuela; Souza, Juiciano. De instrumento a racionalidad: Las tecnologías de la comunicación del difusionismo a la sociedad de la información. Razón y Palabra, 2008, No 62, p.45-58, ISSN 1605-4806.

Red Nacional de Telecentros de Colombia. Brochure de presentación Institucional de la Red Nacional de Telecentros en Colombia, Bogotá, 2009.

Convenio especial de cooperación interinstitucional para la consolidación de la Red Nacional de Telecentros en Colombia, Bogotá, 2008.

. Plan de Desarrollo 2008-2010 de la Red Nacional de Telecentros en Colombia, Bogotá, 2008.

Robinson, Scott S. Telecentros en México, desafíos y posibilidades: Carta abierta a la Comisión Federal de Telecomunicaciones. Razón y Palabra, 1999, No 14, p.89-97, ISSN 1605-4806.

Rúa, Federico. El análisis dinámico de redes sociales con SIENA - Método, discusión y aplicación. Número especial sobre análisis de redes sociales. Revista Empiria de Metodología de Ciencias Sociales. No 10, 151-184. Université des Sciences et Technologies de Lille (Francia) Institut Féderatif des Récherches sur les Sociétés Industrielles (IFRESI), diciembre 2005.

Rueda, Rocio. Apropiación social de las tecnologías de la información: Ciberciudadanías emergentes, Bogotá: Instituto de Estudios Sociales Contemporáneos, IESCO, Universidad Central, 2005.

Cibercultura(s): Capitalismo cognitivo y cultura. Revista Temps d’ Educació, No 34, p. 252-264.

. Tecnologías informáticas: herramientas, metáforas y espacios culturales de investigación. Revista Nómadas, No 18, Mayo de 2003. p. $134-136$.

Sáez Vacas, Fernando. Sociedad de la información, Comunidades Nootrópicas, Nootecnología. CTS+I: Revista Iberoamericana de Ciencia, Tecnología, Sociedad e Innovación, 2001, No 1. p. 2, ISSN 1681-5645.

Salinas, Jesús. Comunidades virtuales y aprendizaje digital, España, 2007, Universidad de las Islas Baleares.

Sánchez Jacob, Eduardo. Red de Telecentros para la transformación Social. Cuadernos Internacionales de tecnología para el desarrollo humano, 2004, No 2, p.45-55, ISSN 1885-8104.

Sánchez Seseña. Luis Miguel. El debate sobre Internet. Un caso: Los Telecentros Publicos. Utopías, nuestra bandera: Revista de debate político, 1999, No 179. p. 137-146, ISSN 1133-567X. 


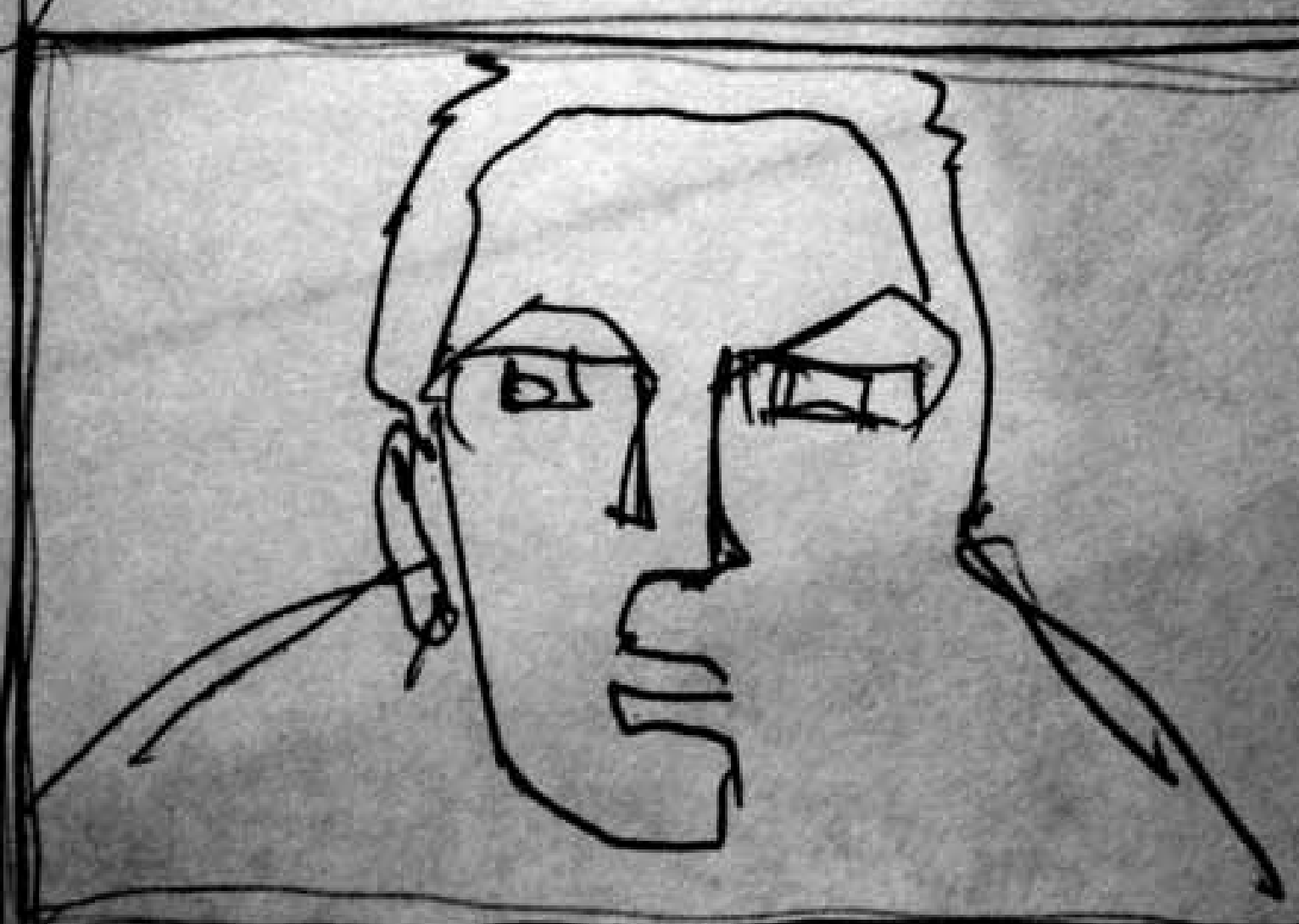

Saperas, Enric. Los efectos cognitivos de la comunicación de masas: Las recientes investigaciones en torno a los efectos de la comunicación de masas, 1970-1986. 1a ed. Barcelona: Ariel, 1987. ISBN 8434412535.

Tamayo, Camilo; Delgado, Juan; Penagos, Julián. Génesis del campo de Internet en Colombia. Elaboración estatal de las relaciones informativas. Signo y Pensamiento, vol. XXVIII, No 54, enerojunio, 2009, p. 238-264. Pontificia Universidad Javeriana.

Terceiro, José. Sociedad digital: del homo sapiens al homo digitalis. Madrid, 1996, Alianza Editorial, 248 páginas. ISBN: 9788420694658

Trejo Delarbre, Raúl. La nueva alfombra mágica. Usos y mitos de Internet, la red de redes. Fundesco, Madrid, 1996.

Unión Internacional de Telecomunicaciones (UIT). Cumbre Mundial de la Sociedad de la Información. Documento finales Ginebra 2003-Túnez 2005, Diciembre de 2005.

. El Informe Perfiles Estadísticos de la Sociedad de la Información, 2009: Región de América. Ginebra,

2009.

Villanueva, Eduardo. Brecha Digital: Descartando un término equívoco. Razón y Palabra, 2006, No 51, p. 35-42. ISSN 1605-4806.

Vizer, Eduardo. ¿Sociedad de la información o de la comunicación? Entre el condicionamiento y la libertad. Signo y Pensamiento, 2004, vol. 23, No 44, p. 41-52, ISSN 0120-4823.

La trama (in)visible de la vida social: comunicación, sentido y realidad. Ed. La Crujía.

Buenos Aires, vol. II: El Poder de la Identidad. Alianza Editorial, Madrid, 1998.

Wenger, Etienne C., MCDERMOTT, Richard, and SNYDER, Williams C., Cultivating Communities of Practice:A Guide to Managing Knowledge, Harvard Business School Press, Cambridge, USA, 2002, 304 pages (ISBN 1-5781-330-8).

Winocur, Rosalía. Nuevas tecnologías y usuarios. La apropiación de las TIC en la vida cotidiana. Telos: Cuadernos de comunicación e innovación, 2007, No 73. p. 109-117, ISSN 0213-084X. 